\title{
Low-dose onabotulinumtoxinA improves urinary symptoms in noncatheterizing patients with MS
}

Mark Tullman, MD, Emmanuel Chartier-Kastler, MD, PhD, Alfred Kohan, MD, Veronique Keppenne, MD, Benjamin M. Brucker, MD, Blair Egerdie, MD, Meryl Mandle, BS, Jean Paul Nicandro, PharmD,

Brenda Jenkins, BS, and Pierre Denys, MD

Neurology ${ }^{\circledR}$ 2018;91:e657-e665. doi:10.1212/WNL.0000000000005991

\section{Abstract}

\section{Objective}

To evaluate the efficacy and safety of onabotulinumtoxinA $100 \mathrm{U}$ in noncatheterizing patients with multiple sclerosis (MS) with urinary incontinence (UI) due to neurogenic detrusor overactivity (NDO).

\section{Methods}

In this randomized, double-blind phase III study, patients received onabotulinumtoxinA $100 \mathrm{U}$ $(n=66)$ or placebo $(n=78)$ as intradetrusor injections via cystoscopy. Assessments included changes from baseline in urinary symptoms, urodynamics, and Incontinence-Quality of Life (I-QOL) total score. Adverse events (AEs) were assessed, including initiation of clean intermittent catheterization (CIC) due to urinary retention.

\section{Results}

OnabotulinumtoxinA vs placebo significantly reduced UI at week 6 ( -3.3 episodes/day vs -1.1 episodes/day, $p<0.001$; primary endpoint). Significantly greater proportions of onabotulinumtoxinA-treated patients achieved $100 \%$ UI reduction $(53.0 \%$ vs $10.3 \%, p<0.001)$. Significant improvements in urodynamics $(p<0.01)$ were observed with onabotulinumtoxinA. Improvements in I-QOL score were significantly greater with onabotulinumtoxinA (40.4 vs 9.9, $p<0.001)$ and $\approx 3$ times the minimally important difference (+11 points). The most common AE was urinary tract infection $(25.8 \%)$. CIC rates were $15.2 \%$ for onabotulinumtoxinA and $2.6 \%$ for placebo.

\section{Conclusion}

In noncatheterizing patients with MS, onabotulinumtoxinA $100 \mathrm{U}$ significantly improved UI and quality of life with lower CIC rates than previously reported with onabotulinumtoxinA 200 U.

\section{ClinicalTrials.gov identifier: \\ NCT01600716.}

\section{Classification of evidence}

This study provides Class I evidence that compared with placebo, $100 \mathrm{U}$ onabotulinumtoxin $\mathrm{A}$ intradetrusor injections significantly reduce UI and improve quality of life in noncatheterizing patients with MS and NDO.

\author{
Correspondence \\ Dr. Tullman \\ mjt2796@bjc.org
}

\section{MORE ONLINE}

$\rightarrow$ Class of Evidence

Criteria for rating

therapeutic and diagnostic studies

NPub.org/coe 


\section{Glossary}

$\mathbf{A E}=$ adverse event; $\mathbf{C I C}=$ clean intermittent catheterization; $\mathbf{I D C}=$ involuntary detrusor contraction; $\mathbf{I}-\mathbf{Q O L}=$ IncontinenceQuality of Life; $\mathbf{M C C}=$ maximum cystometric capacity; $\mathrm{MDP}=$ maximum detrusor pressure; MID = minimally important difference; MS = multiple sclerosis; NDO = neurogenic detrusor overactivity; PVR = postvoid residual; $\mathbf{Q O L}=$ quality of life; TEAE $=$ treatment-emergent adverse event; UI = urinary incontinence; UTI = urinary tract infection.

Most patients with multiple sclerosis (MS) develop neurogenic detrusor overactivity (NDO). ${ }^{1}$ Demyelinating lesions above the level of the pons or involving reticulospinal pathways may lead to uninhibited bladder contractions, resulting in urinary urgency, frequent micturition, and urinary incontinence (UI). ${ }^{2}$ Nonpharmacologic approaches (fluid/ caffeine restriction, pelvic floor muscle exercises, timed voiding) are first-line treatments for urinary storage symptoms. ${ }^{1,3}$ Anticholinergics are commonly used for pharmacologic treatment of symptoms, often with clean intermittent catheterization (CIC) for incomplete bladder emptying or high detrusor pressures, ${ }^{1,3,4}$ but frequently are discontinued because of insufficient efficacy or intolerable side effects. ${ }^{5,6}$

Before approval of onabotulinumtoxinA $200 \mathrm{U}$ for NDO, ${ }^{7}$ surgery (augmentation cystoplasty, urinary diversions) and off-label use of implantable devices (possibly precluding magnetic resonance imaging) were the only treatments for patients with MS and NDO inadequately managed by anticholinergics (with or without CIC). ${ }^{3,4,8}$ OnabotulinumtoxinA intradetrusor injections (a minimally invasive option) were shown to reduce UI and to improve urodynamics and quality of life (QOL) in 2 phase III trials in patients with MS or spinal cord injury. ${ }^{9,10}$ OnabotulinumtoxinA $200 \mathrm{U}$ was well tolerated, although there is a potential risk for urinary retention requiring CIC initiation. In the trials, $31.4 \%$ of patients with MS spontaneously voiding at baseline initiated CIC after treatment. ${ }^{11}$ In contrast, in the nonneurogenic overactive bladder development program, onabotulinumtoxinA $100 \mathrm{U}$ reduced UI with a low CIC rate $(6.1 \%-6.9 \%){ }^{12,13}$

The aim of this study was to assess the efficacy and safety of onabotulinumtoxin $\mathrm{A} 100 \mathrm{U}$ in noncatheterizing patients with MS and NDO to determine whether the lower dose reduces urinary symptoms, maintains spontaneous voiding, and decreases CIC initiation.

\section{Methods}

\section{Study design}

This double-blind, randomized, placebo-controlled phase III trial was conducted at 58 sites in North America and Europe between July 2012 and March 2015. A profile-based stratified randomization was used; patients' baseline parameters of UI episodes per day, anticholinergic use, MS duration, and age assigned them to 1 of 2 strata, after which they were randomized within strata $1: 1$ to onabotulinumtoxinA $100 \mathrm{U}$
(BOTOX, Allergan plc, Irvine, CA) or placebo via an interactive voice or web response system. To prevent possible unblinding, study medication was packaged and labeled identically, which masked the treatment being administered. Study drug was administered via cystoscopy as $301-\mathrm{mL}$ injections evenly distributed into the detrusor, avoiding the trigone. Injections were administered primarily with local anesthesia; however, general anesthesia or no anesthesia was also allowed per physician discretion.

Patients were followed for up to 52 weeks with visits occurring at weeks 2, 6, 12, 24, and 52 (final visit) after treatment. Urinary symptoms, volume per void, and CIC events were recorded in 3-day bladder diaries before each visit. Urodynamic assessments were conducted according to International Continence Society standard guidelines ${ }^{14}$ at screening and week 6 and reviewed by an independent central reviewer. The Incontinence-Quality of Life (I-QOL) questionnaire ${ }^{15}$ was used to assess QOL at baseline, week 6, and week 12. The I-QOL questionnaire is a validated, disease-specific, 22-item patient-reported instrument consisting of 3 domains (avoidance and limiting behavior, psychosocial impact, and social embarrassment) that measures UI-specific QOL. I-QOL total summary and subscale scores range from 0 to 100 , with higher scores reflecting better QOL. The minimally important difference (MID) on the I-QOL has been determined to be +11 points. ${ }^{16}$

Patients could receive up to 2 treatments with study drug. The second treatment was open-label onabotulinumtoxinA that was administered after fulfillment of prespecified retreatment criteria (i.e., $\geq 12$ weeks since the first treatment; the patient requested retreatment and had $\geq 2$ UI episodes over 3 days and a post-void residual [PVR] urine volume $<200 \mathrm{~mL}$ ). Therefore, the placebo-controlled period (the first 12 weeks of the study) is the primary focus of the analyses in this study.

\section{Standard protocol approvals, registrations, and patient consents}

This study (ClinicalTrials.gov identifier NCT01600716) was conducted in accordance with the independent ethics committee or institution review board approval at each study site and in compliance with Good Clinical Practice. All patients provided written informed consent.

\section{Patients}

Eligible patients were adults ( $\geq 18$ years old) with clinically stable MS for $\geq 3$ months who had an Expanded Disability Status Scale score of $\leq 6.5,{ }^{17}$ history of NDO for $\geq 3$ months 
with the presence of an involuntary detrusor contraction (IDC) on urodynamic assessment, and $\geq 3$ UI episodes in a 3-day bladder diary at screening. Their NDO symptoms were inadequately managed by an anticholinergic, which was defined as either an inadequate response after $\geq 4$ weeks of therapy or intolerable side effects after 2 weeks of therapy with an optimized dose. Patients taking an anticholinergic at baseline had to maintain a stable dose throughout the study, and those not taking an anticholinergic had to remain off them. Patients were excluded if they had a PVR urine volume of $>150 \mathrm{~mL}$ at screening or were using CIC to empty the bladder. Patients had to be willing to initiate CIC if necessary. Patients were also excluded if they received previous botulinum toxin therapy for any urologic condition.

\section{Efficacy and safety assessments}

The primary efficacy endpoint was the mean change from baseline at week 6 (primary time point) in UI episodes per day. Other endpoints included proportions of patients achieving $\geq 50 \%$ and $100 \%$ reduction (i.e., "dry" or incontinence free) in UI episodes per day, mean changes from baseline in urgency and micturition episodes, I-QOL total summary and subscale scores, and volume per void. Urodynamic assessments included changes from baseline in mean cystometric capacity (MCC), maximum detrusor pressure (MDP) during the first IDC, and MDP during the storage phase. Duration of effect (time to patient request for retreatment) was also assessed.

Adverse events (AEs) were assessed throughout the study and coded with the Medical Dictionary for Regulatory Activities. PVR urine volume and use of CIC were also assessed. An additional analysis of QOL outcomes was conducted in patients with or without $\mathrm{CIC}$ initiation. The $\mathrm{AE}$ of urinary retention was defined as a PVR urine volume $\geq 350 \mathrm{~mL}$ regardless of symptoms or PVR urine volume $>200 \mathrm{~mL}$ with associated symptoms that required CIC in the investigator's opinion. Residual urine volume was considered an $\mathrm{AE}$ if, in the investigator's opinion, the elevated PVR was clinically significant but did not fulfill the definition for urinary retention. Urinary tract infection (UTI) was defined as a positive urine culture with a bacteriuria count of $>10^{5}$ colony-forming units $/ \mathrm{mL}$ and leukocyturia of $>5$ per highpowered field, regardless of symptoms. MS exacerbation was defined as the appearance of a new symptom or worsening of an old symptom occurring $\geq 30$ days after an earlier event and consistent with a clinical demyelinating event (i.e., optic neuritis, myelitis, cerebellar, brainstem, and/or focal cerebral dysfunction or definite focal sensory symptoms) that developed in the absence of a fever or infection, with a duration of $\geq 24$ hours. Fatigue or bowel or bladder symptoms alone were not deemed an MS exacerbation. All reports of potential MS exacerbations were reviewed by an independent neurologist blinded to treatment assignment (central reviewer).

\section{Statistical analysis}

Efficacy outcomes were analyzed in the intent-to-treat population (all randomized patients). AEs were analyzed in the safety population (all patients who received study treatment).
On the basis of the phase III trials in patients with $\mathrm{NDO}^{9,10}$ an expected common SD of $9.36 \mathrm{UI}$ episodes in a 3-day diary was estimated from data in patients with MS who were noncatheterizing at baseline in the onabotulinumtoxinA $200 \mathrm{U}$ and placebo groups. With this estimate, it was determined that a sample size of 65 patients in each group was expected to provide $85 \%$ power to detect a between-group difference of 5 episodes in change from baseline in the number of UI episodes in the 3-day bladder diary (or mean of $1.67 \mathrm{UI}$ episodes per day), assuming a 2-sided type I error rate of 0.05 . The primary endpoint was assessed with an analysis of covariance model with baseline value as a covariate and treatment and stratification as factors. The Cochran-Mantel-Haenszel method was used to compare the proportions of patients with $\geq 50 \%$ or $100 \%$ reduction in UI episodes per day between the treatment groups by adjusting for the stratification factor. Duration of treatment effect was estimated with Kaplan-Meier analysis. All other efficacy endpoints were analyzed similarly to the primary endpoint.

\section{Primary research question}

Does treatment with a low dose of onabotulinumtoxinA (100 U rather than the approved dose of $200 \mathrm{U}$ for $\mathrm{MS}^{7}$ ) improve urinary symptoms and reduce the need for CIC in noncatheterizing patients with MS and NDO who are inadequately managed by an anticholinergic?

\section{Classification of evidence}

This study provides Class I evidence that compared with placebo, $100 \mathrm{U}$ onabotulinumtoxinA intradetrusor injections significantly reduce UI and improve QOL in noncatheterizing patients with MS and NDO.

\section{Data availability}

Data reported in this manuscript are available within the article or its supplementary materials. Additional data from the Safety and Efficacy Study of OnabotulinumtoxinA for the Treatment of Urinary Incontinence Due to Neurogenic Detrusor Overactivity (NDO) in Non-Catheterizing Patients With Multiple Sclerosis (MS) (study 191622-117, NCT01600716) may be requested (allerganclinicaltrials. com/PatientDataRequest.htm).

\section{Results}

\section{Patients}

The intent-to-treat population consisted of 144 patients randomized to onabotulinumtoxinA $100 \mathrm{U}(\mathrm{n}=66)$ or placebo $(\mathrm{n}=78)$. Overall, $130(90.3 \%)$ patients completed the study. Discontinuations due to lack of efficacy (3 of 144 [2.1\%]) and AEs (2 of 144 [1.4\%]) were low (figure e-1, links.lww.com/ WNL/A623). Demographic and baseline disease characteristics were similar between treatment groups (table 1).

\section{Efficacy}

At week 6 after treatment, UI episodes per day were significantly reduced from baseline with onabotulinumtoxinA vs 
Table 1 Demographics and baseline characteristics (ITT population)

\begin{tabular}{|c|c|c|c|c|}
\hline Characteristic & All patients $(\mathrm{N}=144)$ & Placebo $(n=78)$ & OnabotA $100 \cup(n=66)$ & $p$ Value \\
\hline Age, y & $51.6 \pm 10.3$ & $51.7 \pm 10.3$ & $51.5 \pm 10.4$ & 0.885 \\
\hline Female, n (\%) & $127(88.2)$ & $70(89.7)$ & $57(86.4)$ & 0.531 \\
\hline White, n (\%) & $131(91.0)$ & $69(88.5)$ & $62(93.9)$ & 0.253 \\
\hline Ul episodes per day & $4.3 \pm 2.8$ & $4.3 \pm 2.4$ & $4.2 \pm 3.2$ & 0.765 \\
\hline Urgency episodes per day & $7.2 \pm 4.0$ & $7.5 \pm 4.1$ & $6.8 \pm 3.8$ & 0.307 \\
\hline Micturition episodes per day & $10.3 \pm 3.3$ & $10.4 \pm 3.6$ & $10.0 \pm 2.9$ & 0.470 \\
\hline MCC, mL & $246.0 \pm 135.5$ & $245.7 \pm 133.9$ & $246.4 \pm 138.5$ & 0.975 \\
\hline MDP at first IDC, $\mathrm{cm} \mathrm{H}_{2} \mathrm{O}$ & $36.0 \pm 36.0$ & $36.1 \pm 37.2$ & $35.9 \pm 34.9$ & 0.970 \\
\hline MDP during storage phase, $\mathrm{cm} \mathrm{H}_{2} \mathrm{O}$ & $44.1 \pm 33.9$ & $44.6 \pm 35.1$ & $43.4 \pm 32.5$ & 0.835 \\
\hline Volume per void, $\mathrm{mL}$ & $160.7 \pm 63.6$ & $158.2 \pm 64.6$ & $163.7 \pm 62.6$ & 0.607 \\
\hline Anticholinergic medication use, $\mathrm{n}(\%)$ & $56(39.2)$ & $32(41.6)$ & $24(36.4)$ & 0.526 \\
\hline I-QOL total summary score & $33.4 \pm 19.1$ & $34.2 \pm 21.2$ & $32.4 \pm 16.3$ & 0.592 \\
\hline Avoidance and limiting behavior domain score & $30.0 \pm 17.9$ & $29.9 \pm 18.4$ & $30.1 \pm 17.5$ & 0.941 \\
\hline Psychosocial impact domain score & $39.6 \pm 24.2$ & $40.5 \pm 27.6$ & $38.5 \pm 19.2$ & 0.647 \\
\hline Social embarrassment domain score & $26.5 \pm 20.1$ & $28.0 \pm 21.2$ & $24.5 \pm 18.6$ & 0.317 \\
\hline Duration of MS, $y$ & $14.5 \pm 8.5$ & $14.3 \pm 8.5$ & $14.7 \pm 8.5$ & 0.828 \\
\hline$<12 \mathrm{y}, \mathrm{n}(\%)$ & $60(41.7)$ & $32(41.0)$ & $28(42.4)$ & \\
\hline$\geq 12 y, n(\%)$ & $84(58.3)$ & $46(59.0)$ & $38(57.6)$ & \\
\hline MS disease classification, $\mathrm{n}(\%)$ & & & & 0.240 \\
\hline Relapsing-remitting & $96(66.7)$ & $51(65.4)$ & $45(68.2)$ & \\
\hline Secondary-progressive & $30(20.8)$ & $18(23.1)$ & $12(18.2)$ & \\
\hline Primary-progressive & $15(10.4)$ & $9(11.5)$ & $6(9.1)$ & \\
\hline Progressive-relapsing & $3(2.1)$ & $0(0.0)$ & $3(4.5)$ & \\
\hline \multicolumn{5}{|l|}{ EDSS score } \\
\hline Mean & $4.7 \pm 1.4$ & $4.8 \pm 1.5$ & $4.5 \pm 1.4$ & 0.227 \\
\hline$\leq 3, \mathrm{n}(\%)$ & $24(16.7)$ & $13(16.7)$ & $11(16.7)$ & \\
\hline $3.5-6.5, \mathrm{n}(\%)$ & $120(83.3)$ & $65(83.3)$ & $55(83.3)$ & \\
\hline
\end{tabular}

Abbreviations: EDSS = Expanded Disability Status Scale; IDC = involuntary detrusor contraction; I-QOL = Incontinence-Quality of Life; ITT = intent-to-treat; MCC = mean cystometric capacity; MDP = maximum detrusor pressure; MS = multiple sclerosis; OnabotA = onabotulinumtoxinA; $\mathrm{UI}=$ urinary incontinence Values represent means \pm SD unless otherwise noted.

placebo $(p<0.001$, figure $1 \mathrm{~A})$. Significant decreases in UI episodes with onabotulinumtoxinA $100 \mathrm{U}$ vs placebo were seen as early as week $2(p<0.001)$ and continued through week $12(p<0.001)$. Significantly higher proportions of patients treated with onabotulinumtoxinA vs those treated with placebo achieved $\geq 50 \%$ reduction $(p<0.001)$ and $100 \%$ reduction $(p<0.001)$ in UI episodes per day at week 6 (figure 1B).

Urinary urgency and micturition episodes per day were significantly reduced at week 6 after onabotulinumtoxinA vs placebo ( $p<0.001$, table 2$)$. In addition, onabotulinumtoxinA treatment yielded significantly greater increases in volume per void vs placebo $(p<0.001$, table 2$)$.

Significant improvements were observed in urodynamic outcomes with onabotulinumtoxinA vs placebo. At week 6, a significantly greater increase from baseline in MCC was demonstrated with onabotulinumtoxinA vs placebo, and significantly greater decreases were seen in MDP during the storage phase and during the first IDC vs placebo $(p<0.01$, all endpoints, table 2). 
Figure 1 Effects of onabotulinumtoxinA $100 \mathrm{U}$ vs placebo on UI
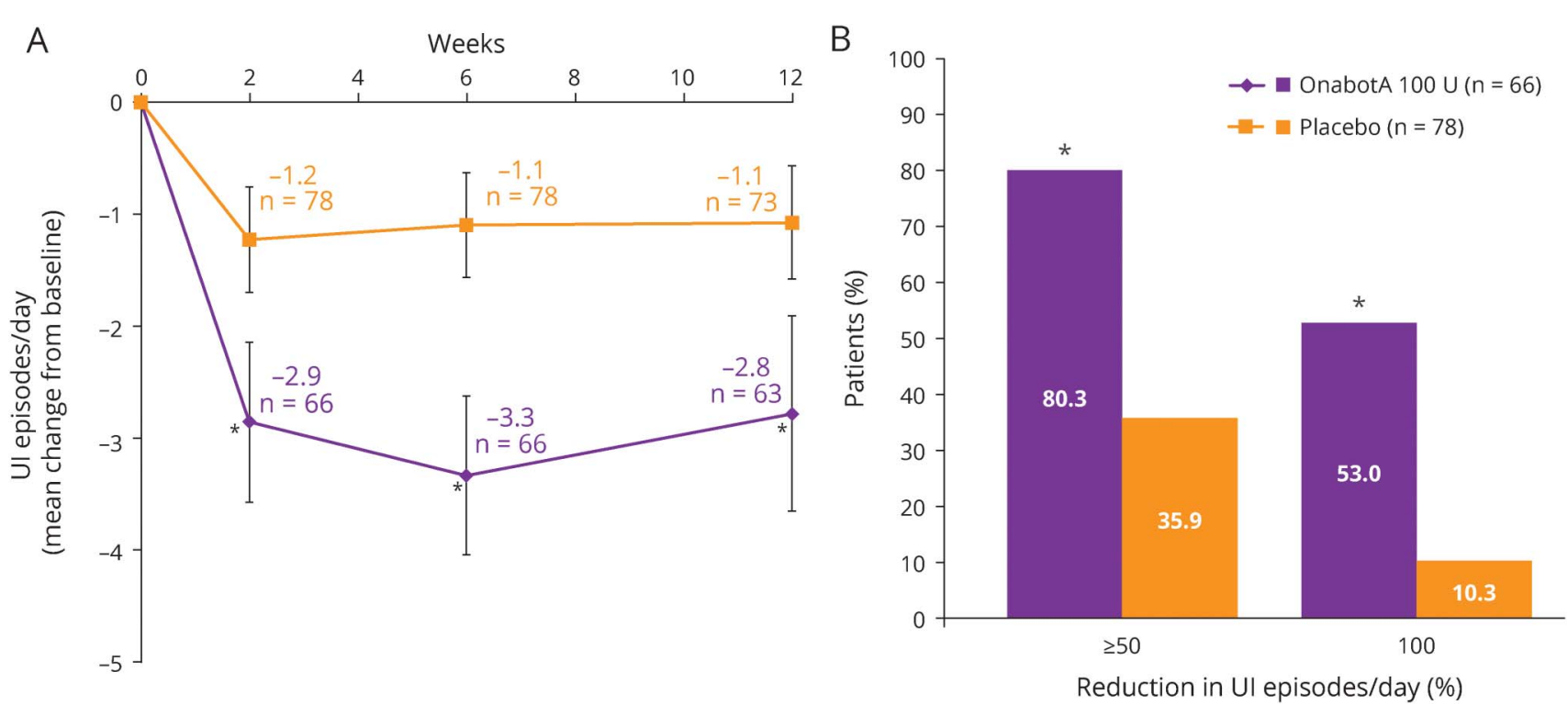

(A) Mean change from baseline in urinary incontinence (UI) episodes at weeks 2,6 , and 12 . (B) Proportion of patients achieving $\geq 50 \%$ and $100 \%$ UI episode reduction at week 6 . Error bars represent $95 \%$ confidence intervals; $n$ values denote the numbers of patients with data available at the evaluated time point after OnabotA (onabotulinumtoxinA) $100 \mathrm{U}$ treatment. ${ }^{*} p<0.001$ vs placebo.

A significantly greater improvement in I-QOL total summary score that was $>3$ times the MID was demonstrated with onabotulinumtoxinA vs placebo at week 6 , which was maintained through week 12 ( $p<0.001$, both time points, figure $2 A)$. Furthermore, significant improvements at week 6 with onabotulinumtoxinA vs placebo were observed across all 3 I-QOL domains (avoidance and limiting behavior, psychosocial impact, and social embarrassment; $p<0.001$, all domains), which were also evident at week $12(p<0.001$, all domains, figure 2, B-D).

The duration of effect (median time to retreatment request) was significantly longer with onabotulinumtoxinA vs placebo ( 51.7 vs 12.6 weeks, $p<0.001$ ). Therefore, only $45.5 \%$ (30 of 66 ) of patients in the onabotulinumtoxinA group and $85.9 \%$ (67 of 78) in the placebo group received treatment 2 with open-label onabotulinumtoxinA (figure e-1, links.lww.com/ $\mathrm{WNL} / \mathrm{A} 623$ ). In patients receiving treatment 2, significant improvements in urinary symptoms from baseline were seen regardless of original treatment assignment (table e-1, links. lww.com/WNL/A624).

\section{Safety}

Treatment-emergent AEs (TEAEs) during the first 12 weeks after treatment 1 were localized largely to the urinary tract (table 3 ). The most frequently reported TEAE was UTI, occurring in $25.8 \%$ (17 of 66 ) of the onabotulinumtoxinAtreated patients and $6.4 \%$ ( 5 of 78 ) of placebo-treated patients (UTIs were symptomatic in $13.6 \%$ [9 of 66] and $1.3 \%$ [ 1 of 78 ] in the onabotulinumtoxinA- and placebo-treated groups, respectively). Recurrent UTIs were observed in the onabotulinumtoxinA-treated group, with 2 episodes in 3 patients and 3 episodes in 2 patients; no recurrent UTIs were reported in the placebo group. Three patients treated with onabotulinumtoxinA were hospitalized for UTI (2 within the first 12 weeks of treatment). No cases of urosepsis were reported. Other TEAEs with onabotulinumtoxinA were residual urine volume (16.7\%) and urinary retention (15.2\%). Vulvovaginal mycotic infection was reported in 2 onabotulinumtoxinA-treated patients.

CIC due to urinary retention was initiated in $15.2 \%$ of patients in the onabotulinumtoxinA group and $2.6 \%$ in the placebo group at any time during treatment cycle 1 for a median duration of 64.0 and 2.0 days, respectively. An analysis to determine whether CIC initiation after onabotulinumtoxinA treatment affected QOL outcomes showed that improvements in I-QOL total score were similar in patients with or without CIC use (48.3 vs 39.1) and 3 to 4 times the MID (figure e-2, links.lww.com/WNL/A623).

MS exacerbations were reported in 2 patients in the placebo group and in no patients in the onabotulinumtoxin A group.

The most common AEs in the 12 weeks after treatment 2 were UTI (24.7\%), urinary retention (15.5\%), bacteriuria (9.3\%), residual urine volume (6.2\%), and dysuria (4.1\%). One patient had an MS exacerbation during treatment 2.

\section{Discussion}

In this randomized, placebo-controlled study in noncatheterizing, stable patients with MS with UI due to NDO, treatment with a low dose $(100 \mathrm{U})$ of onabotulinumtoxinA 
Table 2 Change from baseline in other endpoints at week 6 (ITT population)

\begin{tabular}{|c|c|c|c|}
\hline & Placebo $(n=78)$ & OnabotA $100 \cup(n=66)$ & $p$ Value \\
\hline \multicolumn{4}{|l|}{ Urinary symptoms } \\
\hline Urgency episodes per day & $-1.6(-2.3$ to -0.9$)$ & $-4.3(-5.3$ to -3.3$)$ & $<0.001$ \\
\hline Micturition episodes per day & $-0.8(-1.5$ to -0.1$)$ & $-2.5(-3.3$ to -1.6$)$ & $<0.001$ \\
\hline Volume per void, $\mathrm{mL}$ & $5.1(-7.6$ to 17.8$)$ & 67.6 (43.4 to 91.7$)$ & $<0.001$ \\
\hline \multicolumn{4}{|l|}{ Urodynamic parameters } \\
\hline MCC, mL & $-1.8(-23.7$ to 20.1$)$ & 127.2 (91.8 to 162.5$)$ & $<0.001$ \\
\hline 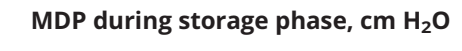 & $-0.5(-7.9$ to 6.9$)$ & $-27.8(-35.2$ to -20.4$)$ & $<0.001$ \\
\hline MDP during first IDC, $\mathrm{cm} \mathrm{H}_{2} \mathrm{O}$ & $3.7(-5.7$ to 13.0$)$ & $-19.6(-35.1$ to -4.0$)$ & 0.007 \\
\hline
\end{tabular}

Abbreviations: IDC = involuntary detrusor contraction; ITT = intent-to-treat; $M C C$ = maximum cystometric capacity; MDP = maximum detrusor pressure; OnabotA = onabotulinumtoxinA.

Values represent means ( $95 \%$ confidence intervals).

resulted in statistically and clinically significant reductions in daily episodes of UI, urgency, micturition, and volume per void compared with placebo. More than half the patients (53\%) treated with onabotulinumtoxinA became incontinence free (i.e., "dry") at week 6 after treatment (primary endpoint). These decreases in urinary symptoms corresponded well with objective measures of bladder function: significant improvements were observed in urodynamic parameters after onabotulinumtoxinA treatment, including increases in MCC (bladder capacity) and lowering of MDP (bladder pressure).

Whereas the registrational phase III studies with $200 \mathrm{U}$ onabotulinumtoxinA have shown similar improvements in urinary symptoms in patients with MS or spinal cord injury and NDO,, 10 this study also demonstrated significant improvements in urinary urgency, which was not measured in the earlier studies. Considering that urgency is the most commonly reported and one of the most bothersome urinary symptoms in patients with MS and NDO, this is an important outcome of this study. ${ }^{18,19}$

The efficacy of onabotulinumtoxinA treatment in this study has practical implications for patients' daily lives as evidenced by the significant improvements in QOL resulting from reductions in urinary symptoms. Patients achieved improvements in their I-QOL total summary score that met/exceeded the MID at both 6 and 12 weeks after treatment with onabotulinumtoxinA. Notably, additional improvements in specific dimensions of patients' QOL (i.e., avoidance and limiting behavior, psychosocial impact, and social embarrassment) were observed. Some studies have concluded that bladder dysfunction is one of the key determinants of poor QOL in patients with $\mathrm{MS}^{20}$; $\approx 70 \%$ consider urinary symptoms to have moderate to high negative effects on QOL. ${ }^{21}$ Given that improving QOL is an important treatment goal in patients with $\mathrm{MS}^{22}$ results from this study provide further evidence of the clinical benefits of onabotulinumtoxin $A$ and their positive effect on QOL, particularly at the lower dose of onabotulinumtoxinA.

Another important treatment goal for patients with NDO is the preservation of renal function by maintaining normal detrusor pressures. ${ }^{3}$ In the present study, onabotulinumtoxinA significantly reduced MDP during the bladder storage phase and at the first intradetrusor contraction. The clinical implications of this finding are notable because the reduction and maintenance of bladder pressures to $<40 \mathrm{~cm} \mathrm{H}_{2} \mathrm{O}$ during filling is considered a long-term treatment goal for some patients. ${ }^{23}$

While the treatment response to onabotulinumtoxin $\mathrm{A} 100 \mathrm{U}$ in this study is consistent with the results from the phase III trials of onabotulinumtoxinA $200 \mathrm{U}$ in patients with MS or spinal cord injury, a direct comparison with earlier studies has inherent limitations: the $100-\mathrm{U}$ and $200-\mathrm{U}$ doses were investigated in separate studies and under varying study conditions, including different sites, study timing (before vs after regulatory agency approval of onabotulinumtoxin A), and trial methodologies (e.g., use of a 7- vs 3-day diary for the primary endpoint), all of which would confound a direct comparison. However, while recognizing these limitations, we found that both the 200-U and 100-U doses of onabotulinumtoxinA demonstrated clinically significant efficacy in their respective studies at weeks 2, 6, and 12 after treatment. In the phase III registrational studies, $200 \mathrm{U}$ was shown to be an effective dose in the general NDO population in both catheterizing and noncatheterizing patients with MS or spinal cord injury. ${ }^{9,10}$ Thus, the results from the present study extend these previous findings in the specific subpopulation of noncatheterizing patients with MS, demonstrating that onabotulinumtoxinA $100 \mathrm{U}$ is also an effective and well-tolerated dose in these patients. Most important, the risk of CIC with onabotulinumtoxinA $100 \mathrm{U}$ in this study was lower (15.2\%) than the $31.4 \%$ CIC rate with onabotulinumtoxin $\mathrm{A} 200 \mathrm{U}$ among the subset of noncatheterizing patients with MS in the phase III trials. ${ }^{11}$ 
Figure 2 Effects of onabotulinumtoxinA $100 \mathrm{U}$ vs placebo on quality of life
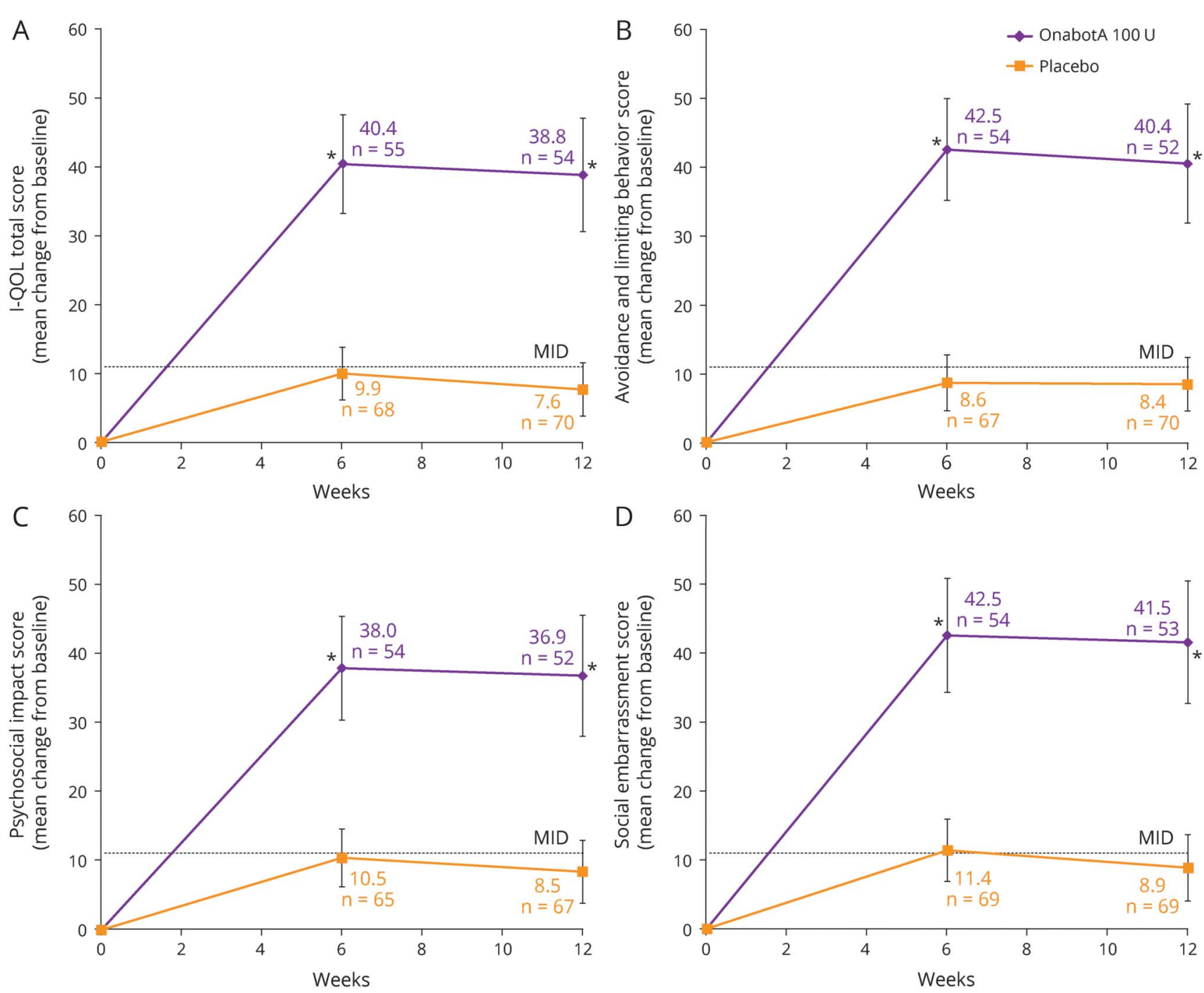

(A) Mean change from baseline in Incontinence-Quality of Life (I-QOL) total summary score. (B) Mean change from baseline in avoidance and limiting behavior. (C) Mean change from baseline in psychosocial impact. (D) Mean change from baseline in social embarrassment. Error bars represent $95 \%$ confidence intervals; $n$ values denote the numbers of patients with data available at the evaluated time point after OnabotA (onabotulinumtoxinA) treatment. ${ }^{*} p<0.001$ vs placebo. MID = minimally important difference $(+11$ points $)$.

In this study, most $(85 \%, 56$ of 66$)$ patients did not need to initiate CIC and preserved their ability to spontaneously void, which highlights the clinical value offered by a lower dose of onabotulinumtoxin $\mathrm{A} 100 \mathrm{U}$ as a feasible treatment option for noncatheterizing patients with MS. Despite the inconveniences of catheterization, patients who used CIC have reported improvements in QOL. ${ }^{24,25}$ Indeed, among the 10 patients who initiated $\mathrm{CIC}$ after onabotulinumtoxinA treatment in this analysis, I-QOL improvements were substantially greater than with placebo and similar to improvements in those who did not use CIC.

Onabotulinumtoxin A $100 \mathrm{U}$ was well tolerated with no unexpected side effects, and TEAEs were localized primarily to the urinary tract; the most common AEs were UTIs, approximately half of which were symptom free. While UTI rates (including symptomatic, asymptomatic, and recurrent) in the
onabotulinumtoxinA treatment group were higher than in the placebo group in this trial, they were slightly lower than that seen in a post hoc analysis of the previous studies in which the rate of UTI with onabotulinumtoxinA $200 \mathrm{U}$ was $33.7 \%$ among patients with MS not using CIC at baseline (Allergan plc; data on file). However, it is important for health care providers to communicate potential risks when discussing onabotulinumtoxinA $100 \mathrm{U}$ as a treatment option for patients with MS and NDO.

Dosing and findings reported in this study are specific to onabotulinumtoxinA. This formulation is not interchangeable with other botulinum toxin products, and units cannot be converted with a dose ratio. ${ }^{26}$

This trial demonstrates that in noncatheterizing patients with MS and NDO, treatment with onabotulinumtoxinA $100 \mathrm{U}$ 
Table 3 TEAEs $\geq 3 \%$ within the first 12 weeks of treatment cycle 1 (safety population)

\begin{tabular}{|c|c|c|}
\hline Events & $\begin{array}{l}\text { Placebo } \\
(n=78), \\
n(\%)\end{array}$ & $\begin{array}{l}\text { OnabotA } \\
100 \cup(n=66), \\
n(\%)\end{array}$ \\
\hline Overall & $38(48.7)$ & $45(68.2)$ \\
\hline UTI & $5(6.4)$ & $17(25.8)^{\mathrm{b}}$ \\
\hline Symptomatic & $1(1.3)$ & $9(13.6)$ \\
\hline Asymptomatic & $4(5.1)$ & $8(12.1)$ \\
\hline Residual urine volume $^{c}$ & $1(1.3)$ & $11(16.7)^{d}$ \\
\hline Urinary retention ${ }^{\mathbf{e}}$ & $1(1.3)$ & $10(15.2)^{f}$ \\
\hline Bacteriuria & $4(5.1)$ & $6(9.1)$ \\
\hline Dysuria & $1(1.3)$ & $3(4.5)$ \\
\hline Diarrhea & $3(3.8)$ & $1(1.5)$ \\
\hline Arthralgia & $1(1.3)$ & $2(3.0)$ \\
\hline Bladder discomfort & $0(0)$ & $2(3.0)$ \\
\hline Ear infection & $0(0)$ & $2(3.0)$ \\
\hline Fall & $1(1.3)$ & $2(3.0)$ \\
\hline Hematuria & $5(6.4)$ & $2(3.0)$ \\
\hline Renal cyst & $1(1.3)$ & $2(3.0)$ \\
\hline Leukocyturia & $4(5.1)$ & $2(3.0)$ \\
\hline Vulvovaginal mycotic infection ${ }^{g}$ & $0(0)$ & $2(3.5)$ \\
\hline $\begin{array}{l}\text { Patients initiating } \mathrm{CIC} \text { at any time during } \\
\text { treatment cycle 1, } \%\end{array}$ & $2(2.6)$ & $10(15.2)$ \\
\hline
\end{tabular}

Abbreviations: $\mathrm{CIC}=$ clean intermittent catheterization; Onabot $\mathrm{A}=$ onabotulinumtoxinA; TEAE = treatment-emergent adverse event; $\mathrm{UTI}=$ urinary tract infection.

a Defined as a positive urine culture with a bacteriuria count of $>10^{5}$ colonyforming units $/ \mathrm{mL}$ and leukocyturia of $>5$ per high-powered field, regardless of symptoms.

${ }^{\mathrm{b}} p=0.001$ vs placebo, Pearson $\chi^{2}$ test.

c Defined as clinically significant elevated postvoid residual (PVR) urine volume in the investigator's opinion but did not fulfill the definition for urinary retention.

${ }^{\mathrm{d}} p<0.001$ vs placebo, Pearson $\chi^{2}$ test.

e Defined as PVR $\geq 350 \mathrm{~mL}$ regardless of symptoms or PVR $\geq 200$ and $<350 \mathrm{~mL}$ with associated symptoms that required $\mathrm{ClC}$ in the investigator's opinion. ${ }^{f} p=0.002$ vs placebo, Pearson $\chi^{2}$ test.

${ }^{g}$ Based on female study population only.

results in significant and clinically relevant improvements in UI and other urinary symptoms, urodynamics, and QOL with lower CIC and UTI rates than previously reported with onabotulinumtoxinA $200 \mathrm{U}$.

\section{Author contributions}

Mark Tullman: drafting/revising the study manuscript, analysis and interpretation of data. Emmanuel Chartier-Kastler: study design and concept, drafting/revising the study manuscript, analysis and interpretation of data, study investigator. Alfred Kohan, Veronique Keppenne, Benjamin M. Brucker, and Blair Egerdie: drafting/revising the study manuscript, analysis and interpretation of data, study investigator. Meryl
Mandle: writing/editorial assistance, preparation of figures and tables. Jean Paul Nicandro: technical support, analysis and interpretation of data, drafting/revising the study manuscript. Brenda Jenkins: study design and concept, technical support, analysis and interpretation of data, drafting/revising the study manuscript. Pierre Denys: drafting/revising the study manuscript, analysis and interpretation of data, study investigator.

\section{Acknowledgment}

The authors acknowledge the study investigators for their contributions to data acquisition: Canada: Karen Ethans, Sender Herschorn, Jerzy Gajewski, Gary Steinhoff, Le Mai Tu, James Wilson; Czech Republic: Jiri Heracek, Pavel Navratil, Vladimir Student; France: Gerard Amarenco, Aurelien Descazeaud, Gilles Karsenty, Loic Lenormand, Alain Ruffion; Poland: Lucyna Grochala, Thomasz Rechberger, Janusz Zajda; Portugal: Mario J. Gomes, Andre Silva; Russia: Salman AlShukri, Sergey Gorelov; United States: Philip Aliotta, Christopher Chermansky, Kevin Cline, Mitchell Efros, Jonathan Fialkov, Brian Flynn, Kris Gaston, David Ginsberg, David Glazier, Evan Goldfischer, Angelo Gousse, Jennifer Gruenenfelder, Douglass Hale, Karny Jacoby, Melissa Kaufman, Kent Krejci, Ajay Nehra, Victor Nitti, David Oselinsky, Jill Peters-Gee, Peter Sand, Paul Siami, Patrick Shenot, Jeffrey Small, Thomas Williams, Tracey Wilson. The authors also thank Andrew Magyar for his contribution to biostatistical analyses of data.

\section{Study funding}

This study and its analysis were sponsored by Allergan plc, Irvine, CA.

\section{Disclosure}

M. Tullman has been a consultant for Allergan plc. E. ChartierKastler has been a consultant and advisor for Allergan plc, Astellas, Boston Scientific, Coloplast, Ferring, Medtronic, Pierre Fabre Médicaments, Promedon, and Uromems; an investigator for Allergan plc, Astellas, Axonics, Coloplast, GT Urological, and Ipsen Biotech; a meeting participant or lecturer for Allergan plc, Astellas, Boston Scientific, Coloplast, Medtronic, Pierre Fabre Médicaments, and Promedon; and an investigator for Allergan plc, Coloplast, and Medtronic. A. Kohan has been an investigator for Allergan plc, Ipsen, Myovant, and Watson, as well as a speaker for Allergan plc and Watson. $\mathrm{V}$. Keppenne has been a consultant and advisor for Allergan plc and Pfizer; has been an investigator for Allergan plc, Astellas, and Pfizer; has an investment interest in Allergan plc, Astellas, and Coloplast; has been a meeting participant/lecturer for Allergan plc, Coloplast, and Wellspect; and has conducted trials for Allergan plc, Astellas, Coloplast, Pfizer, and Wellspect. B. Brucker has been a consultant and advisor for Allegan plc and Watkins-Conti; has been an investigator for Ipsen and Medtronic; and has participated in studies for Allergan plc and Watkins-Conti. B. Egerdie has been a consultant and advisor for Abbott, Allergan plc, Amgen, Astellas, Bayer HealthCare, Eli Lilly, GlaxoSmithKline, Pfizer, Protox Therapeutics, and 
Spectrum; a speaker for Abbott, Allergan plc, Amgen, Astellas, AstraZeneca, Bayer HealthCare, Eli Lilly, GlaxoSmithKline, and Pfizer; and coordinating investigator for Allergan and Eli Lilly. M. Mandle provided writing assistance for manuscript development that was funded by Allergan plc. J. Nicandro and B. Jenkins are employees of Allergan plc. P. Denys has been an advisor and consultant for Allergan plc, Coloplast, Ipsen, Medtronic, and Wellspect; a speaker for Coloplast, Medtronic, and Wellspect; and an investigator for Allergan and Ipsen. Go to Neurology.org/ $\mathrm{N}$ for full disclosures.

Received July 27, 2017. Accepted in final form May 14, 2018.

\section{References}

1. Phe V, Chartier-Kastler E, Panicker JN. Management of neurogenic bladder in patients with multiple sclerosis. Nat Rev Urol 2016;13:275-288.

2. Riley CS. Multiple sclerosis and allied demyelinating diseases. In: Louis ED, Mayer SA, Rowland LP, editors. Merritt's Neurology, 13th ed. Philadelphia: Wolters Kluwer; 2016:593-610.

3. Stohrer M, Blok B, Castro-Diaz D, et al. EAU guidelines on neurogenic lower urinary tract dysfunction. Eur Urol 2009;56:81-88.

4. Fowler CJ, Panicker JN, Drake M, et al. A UK consensus on the management of the bladder in multiple sclerosis. J Neurol Neurosurg Psychiatry 2009;80:470-477.

5. Manack A, Motsko SP, Haag-Molkenteller C, et al. Epidemiology and healthcare utilization of neurogenic bladder patients in a US claims database. Neurourol Urodyn 2011;30:395-401.

6. Khalaf KM, Coyne KS, Globe DR, Armstrong EP, Malone DC, Burks J. Lower urinary tract symptom prevalence and management among patients with multiple sclerosis. Int J MS Care 2015; 17:14-25.

7. BOTOX [package insert]. Irvine: Allergan Pharmaceuticals Ireland; 2016.

8. Sanford MT, Suskind AM. Neuromodulation in neurogenic bladder. Transl Androl Urol 2016;5:117-126.

9. Cruz F, Herschorn S, Aliotta P, et al. Efficacy and safety of onabotulinumtoxinA in patients with urinary incontinence due to neurogenic detrusor overactivity: a randomised, double-blind, placebo-controlled trial. Eur Urol 2011;60:742-750.

10. Ginsberg D, Gousse A, Keppenne V, et al. Phase 3 efficacy and tolerability study of onabotulinumtoxinA for urinary incontinence from neurogenic detrusor overactivity. J Urol 2012;187:2131-2139.

11. Ginsberg D, Cruz F, Herschorn S, et al. OnabotulinumtoxinA is effective in patients with urinary incontinence due to neurogenic detrusor overactivity [corrected] regardless of concomitant anticholinergic use or neurologic etiology. Adv Ther 2013; 30:819-833.

12. Nitti VW, Dmochowski R, Herschorn S, et al. OnabotulinumtoxinA for the treatment of patients with overactive bladder and urinary incontinence: results of a phase 3 , randomized, placebo controlled trial. J Urol 2013;189:2186-2193.

13. Chapple C, Sievert KD, MacDiarmid S, et al. OnabotulinumtoxinA $100 \mathrm{U}$ significantly improves all idiopathic overactive bladder symptoms and quality of life in patients with overactive bladder and urinary incontinence: a randomised, double-blind, placebo-controlled trial. Eur Urol 2013;64:249-256.

14. Homma Y, Batista J, Bauer S, et al. Urodynamics. In: Abrams P, Cardozo L, Khoury S, Wein A, editors. Incontinence. 2nd International Consultation on Incontinence. Plymouth: Plymbridge Distributors Ltd; 2002:317-372.

15. Patrick DL, Martin ML, Bushnell DM, Yalcin I, Wagner TH, Buesching DP. Quality of life of women with urinary incontinence: further development of the Incontinence Quality of Life Instrument (I-QOL). Urology 1999;53:71-76.

16. Schurch B, Denys P, Kozma CM, Reese PR, Slaton T, Barron R. Reliability and validity of the Incontinence Quality of Life questionnaire in patients with neurogenic urinary incontinence. Arch Phys Med Rehabil 2007;88:646-652.

17. Kurtzke JF. Rating neurologic impairment in multiple sclerosis: an expanded disability status scale (EDSS). Neurology 1983;33:1444-1452.

18. Betts CD, D'Mellow MT, Fowler CJ. Urinary symptoms and the neurological features of bladder dysfunction in multiple sclerosis. J Neurol Neurosurg Psychiatry 1993;56: $245-250$.

19. Khalaf KM, Coyne KS, Globe DR, et al. The impact of lower urinary tract symptoms on health-related quality of life among patients with multiple sclerosis. Neurourol Urodyn 2016;35:48-54.

20. Zecca C, Riccitelli GC, Disanto G, et al. Urinary incontinence in multiple sclerosis: prevalence, severity and impact on patients' quality of life. Eur J Neurol 2016;23: $1228-1234$

21. Hemmett L, Holmes J, Barnes M, Russell N. What drives quality of life in multiple sclerosis? QJM 2004;97:671-676.

22. Genty M, Devy R, Edan G, Lehert P. Effect of cognitive behavioral therapy on MS patients' quality of life. A multi-centre controlled trial. Ann Phys Rehabil Med 2016; 59S:e41-e42.

23. de Seze M, Ruffion A, Denys P, Joseph PA, Perrouin-Verbe B. The neurogenic bladder in multiple sclerosis: review of the literature and proposal of management guidelines. Mult Scler 2007;13:915-928.

24. Girotti ME, MacCornick S, Perisse H, Batezini NS, Almeida FG. Determining the variables associated to clean intermittent self-catheterization adherence rate: one-year follow-up study. Int Braz J Urol 2011;37:766-772.

25. Kessler TM, Ryu G, Burkhard FC. Clean intermittent self-catheterization: a burden for the patient? Neurourol Urodyn 2009;28:18-21.

26. Brin MF, James C, Maltman J. Botulinum toxin type A products are not interchangeable: a review of the evidence. Biologics 2014;8:227-241. 


\section{Neurology}

\section{Low-dose onabotulinumtoxinA improves urinary symptoms in noncatheterizing patients with MS}

Mark Tullman, Emmanuel Chartier-Kastler, Alfred Kohan, et al.

Neurology 2018;91;e657-e665 Published Online before print July 20, 2018

DOI 10.1212/WNL.0000000000005991

This information is current as of July 20, 2018

\section{Updated Information \&} Services

References

Subspecialty Collections

Permissions \& Licensing

Reprints including high resolution figures, can be found at: http://n.neurology.org/content/91/7/e657.full

This article cites 23 articles, 3 of which you can access for free at: http://n.neurology.org/content/91/7/e657.full\#ref-list-1

This article, along with others on similar topics, appears in the following collection(s):

Multiple sclerosis

http://n.neurology.org/cgi/collection/multiple_sclerosis Quality of life

http://n.neurology.org/cgi/collection/quality_of_life

Information about reproducing this article in parts (figures,tables) or in its entirety can be found online at:

http://www.neurology.org/about/about_the_journal\#permissions

Information about ordering reprints can be found online:

http://n.neurology.org/subscribers/advertise

Neurology ${ }^{\circledR}$ is the official journal of the American Academy of Neurology. Published continuously since 1951, it is now a weekly with 48 issues per year. Copyright Copyright ( 2018 The Author(s). Published by Wolters Kluwer Health, Inc. on behalf of the American Academy of Neurology.. All rights reserved. Print ISSN: 0028-3878. Online ISSN: 1526-632X.

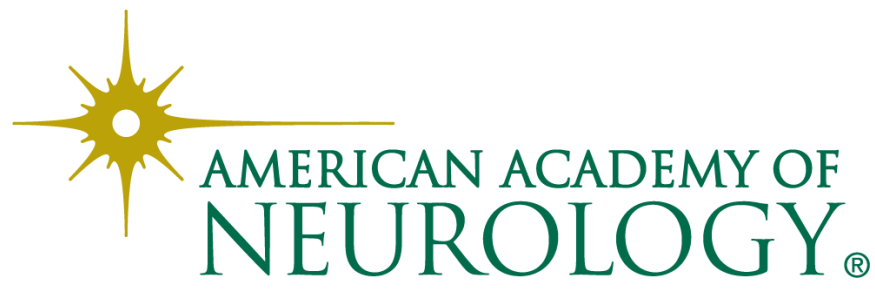

